\title{
Unravelling gossamer with boxing gloves: problems in explaining the decline in smoking
}

\author{
Simon Chapman
}

For about three decades countries such as Australia, Great Britain, and the United States have been turning up the heat on tobacco advertising. Encouraging, sometimes dramatic falls in consumption have followed. On any given day in 1993 smokers in such countries are exposed to a welter of news, information, persuasion, and policies designed to turn them off smoking. For a long time explanations and evaluations of the effects of these policies and interventions have been tied to oversimplified causal models when the reality is rather more messy and complicated. Four factors largely explain the reluctance of researchers to move beyond these models: the reductionist tradition of science; the explanatory privileging of recent events and factors; pragmatic concern for policy "tractable" factors; and the relation of funding to the evaluative process. Broader research approaches to understanding changes in complex behaviours such as smoking are required-for example, qualitative methods.

Between 1965 and 1991 cigarette consumption per adult (15 and over) fell by $33.3 \%$ in Australia from $2740 \mathrm{~g}$ to $1827 \mathrm{~g}$ (figure). ${ }^{1}$ For 13 years of this period (1964-1976) consumption remained virtually unchanged. However, from 1977, the year after direct advertising of cigarettes was banned nationally on radio and television, the average annual fall has been $2 \cdot 2 \%$. And since 1983 , when the first of a series of large scale mass media campaigns started, ${ }^{2}$ the fall has increased still further to a mean $2.5 \%$ per year.

Estimated total consumption of tobacco and cigarettes per person aged 15 years and over in Australia, 1965-91

Department of Community Medicine, University of Sydney, Westmead Hospital, Westmead NSW 2145, Australia Simon Chapman, senior lecturer

BM于 1993;307:429-32

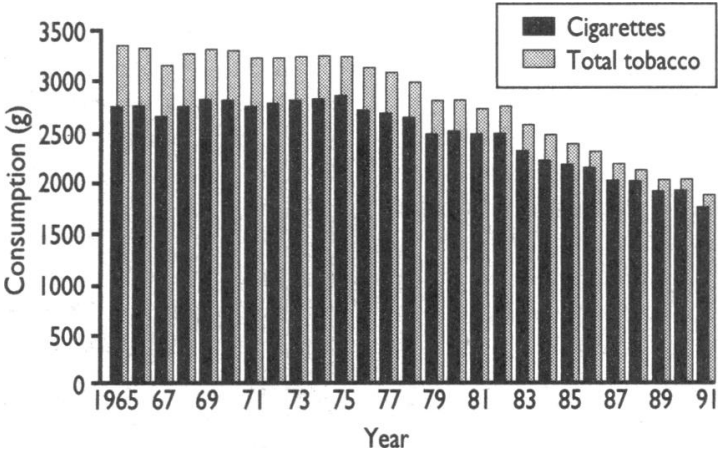

How do we explain this internationally acclaimed success story in modern public health? Is it reasonable to nominate, as implied above, particular policy or intervention landmarks such as advertising bans or large government campaigns as the probable cause of the change rather than other less prominent and tangible but perhaps more pervasive influences barely deserving to be described as "interventions"? How can decisions be made about the success or failure of particular programmes and policies intended to further this trend? What limitations are there on the ability of quantitative research methods to address these questions?

In this paper I explore these questions through consideration of some awkward problems raised by a case study. I argue that the ambition to attribute specific preventive or cessation effects to particular tobacco control interventions is highly problematic when there is interplay of continuous, uncontrolled, unmeasured, and sometimes unmeasurable variables intended to influence consumption. Such an ambition reflects a reductionist epistemology that is largely incapable of illuminating the complex nature of how it is that people fail to take up smoking, succeed in stopping smoking, or succeed in reducing their consumption-the three determinants of falling tobacco consumption per head. Attempts to attribute causal effects to specific interventions when interventions and influences are many are inevitably fraught with highly questionable assumptions; these assumptions serve the interests of those requiring simplistic, quantified explanations of what are in fact highly complex phenomena. These explanations have more to do with the contexts in which attempts at explanation take place and with the politics of programme funding than they do with any dedication to a full account of the changing phenomenon of smoking in countries such as Australia.

\section{A day in the life of an Australian smoker...}

Consider a recent day in the life of an Australian smoker, John. As he wakes, John listens to a news item about a government decision to end all remaining forms of tobacco advertising. ${ }^{3}$ Since the mid-1970s he has woken to many similar announcements about various forms of tobacco advertising. These have occasioned discussions at his office and in social gatherings, where smoking has become a common and sometimes highly charged topic of conversation. Newspapers have also been thick with news about smoking. In 1988, for example, he might have read up to 1600 separate items in newspapers alone, of which only $17 \%$ would have delivered even a vaguely comforting message.

As John smoked at the breakfast table his two children playfully chorused their usual antismoking slogans "Smokers suck! But we get half the muck!" and "Kiss a non-smoker... taste the difference." It seemed that there had been dozens of these taunts over the years. Undoubtedly they had picked them up from school, where he knew that they were regularly given lessons on the health consequences of smoking.

His wife, who didn't smoke, had, like a lot of people, slowly turned into someone who actively disliked smoking. She had recently begun seriously talking to him about whether he might go outside when he wanted to smoke. In making this request, it seemed to John that she was not really being overzealous.

On the way to the station he stopped to buy a new packet of cigarettes. Proffering $\$ A 4.55$ for his usual packet of 30 , he was reminded by the shop assistant that they had now gone up by 20 cents a packet in the latest federal budget. John had calculated that by smoking a packet a day he was spending \$A1734 a year on cigarettes-the price of a 10 day holiday in a luxury hotel in Bali.

Boarding the train, he pondered that here was yet another place he couldn't smoke. Public transport had gone smoke free in 1976, joined in 1990 by all domestic flights in Australia and in 1992 by a ban on smoking on an increasing number of international routes and even a total ban inside Australian air terminals.

As he read the morning newspaper he noticed 


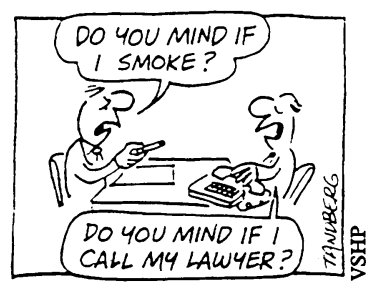

In Australia smoking has become an emotive issue how many of the classified advertisements for shared accommodation specified that only non-smokers need apply. Of 335 advertisements that day, $42 \%$ specified this requirement ${ }^{6}$ - a higher rate than any other quality sought by advertisers. He also noticed that every government job advertisement and a not inconsiderable number of private sector advertisements stated that "a smoke free workplace was company policy." Browsing through the lonely hearts advertisements he was again struck by how many of these people sought a partner who was a non-smoker. And then he was confronted by a full page advertisement from a life insurance company offering substantially reduced rates for non-smokers. ${ }^{7}$ Arriving at work, John stubbed out what would be his last cigarette until lunchtime. In 1988 his office had introduced a total smoking ban. Since then there had been almost a stampede throughout the Australian business world to do the same. By $1992,58 \%$ of the top 139 companies in one state had total bans, with over half of these having introduced them in the previous 12 months. ${ }^{8} \mathrm{~A}$ successful law suit by a worker whose asthma has been severely aggravated by passive smoking in her workplace seemed certain to hasten this process. ${ }^{9}{ }^{10}$ The ban at work had certainly reduced John's own consumption. It had been estimated that the average smoking office worker had reduced daily consumption by around a quarter" 1 and that the workplace bans would cost the Australian tobacco industry $\$ \mathrm{~A} 73$ million in lost sales a year. ${ }^{12}$

At lunchtime John went with some colleagues to a nearby Pizza Hut restaurant. The whole chain had recently gone smoke free, reflecting an overwhelming demand in the community for smoke free dining. ${ }^{13}{ }^{14}$ $\mathrm{He}$ then passed a street sign warning him that he could be fined for discarding his cigarette end in the street ${ }^{15}$ the non-biodegradability of cigarette ends made them a major pollution problem, especially in a city where stormwater ran into the picturesque harbour around which the city was built. Being environmentally conscious, he felt awkward about how he usually disposed of his cigarette ends.

At home John saw a report on the television news linking smoking with yet another dreaded diseaseleukaemia. "Was there anything that smoking didn't cause?" he thought to himself, reflecting on all the news reports he had heard about the subject over the years. Being a sports fan, he switched between the channels showing the national football and basketball competitions. And there it was again: antismoking sponsorship messages on the sidelines and even on the players' clothing. And then to put the icing on the cake, a gory government advertisement showing how much black tar a smoker would inhale in a year was shown several times during commercial breaks.

The next day John decided that he would finally stop smoking. Over the next 12 months he made three or four unsuccessful attempts, ${ }^{17}$ one inspired by a brief warning given to him by his doctor ${ }^{18}$ and another after prompting from his pharmacist to try non-prescribed nicotine gum. Eighteen months after his initial decision he smoked what would be his last cigarette. In doing so, he joined roughly 3.8 million Australian adults who identify themselves as former smokers. ${ }^{19}$

Shortly after he finally stopped smoking he was phoned by a researcher evaluating a stop smoking media campaign by the government. John joined those who responded that they had seen the campaign; who strongly agreed that the campaign made them think about stopping; and who responded (unprompted) that health reasons, social unacceptability, and cost were the three main reasons they had stopped smoking. ${ }^{20}$

The researchers subsequently wrote a scientific article in which they claimed that their statewide media campaign was probably the reason why the rate of stopping smoking in the state was higher than that in other states. This claim was based on extrapolations made from the sample of aggregated recent ex-smokers such as John.

\section{Discussion}

How do we explain John's decision to stop smoking? What do we make of a community cessation rate extrapolated from data including John's responses and its partial attribution to the government campaign? And what should we make of John's account of why he stopped? In the published evaluative research of tobacco control such questions are seldom asked and are pursued even less often. When questions of attribution are assessed, the influence of a particular variable such as advertising or a health education campaign is usually examined with standard pre-post or intervention-control group designs. Occasionally, a limited number of potential confounders such as price changes are incorporated into such studies. Control areas are seldom if ever matched with intervention areas for anything remotely like the range of variables described in the above case study. Essentially qualitative variables such as tobacco advertising are conveniently homogenised into measurable units such as cost, as if all advertising campaigns could be considered of equal impact. ${ }^{21}$ Such an assumption would be news indeed to many in the advertising industry who know too well how many of their efforts seem to make little difference to brand sales.

Smokers have obviously been exposed to a plethora of interventions, campaigns, and influences during their lifetime. From John's perspective these have not occurred in any neat, sequential order or in any way that would allow him to measure reliably their respective influence on his gradually changing perception of his own smoking and the evolution of his decision to stop. Indeed at many times in John's recent smoking history it would have been quite impossible to isolate and measure the effects of any one of up to a dozen concurrent variables. Quantitative evaluative research processes avoid the methodological imbroglios that are inherent in accepting the reality of the dynamic interplay of the sort of factors described in the case study. There are at least four outstanding explanations for this.

\section{REDUCTIONIST EPISTEMOLOGY}

Evaluative research in tobacco control is almost entirely within the scientific tradition. This tradition assumes a reductionist epistemology whereby the task of science is to discover and measure the exact relation between variables. Any difficulties in assessing these relations are assumed to lie with the imprecision of the methods used to assess them and not with the very conception of the nature of how it is that a complex behaviour such as smoking changes throughout a population or a subject's lifetime. The ambition to measure exactly the assumed relation is seen as a task worthy of pursuit, whereas consideration of the gestalt of how various cultural, economic, organisational, and educational factors combine to influence smoking behaviour is viewed as messy and unscientific. The only manageable truths in this tradition are those that are simple and uncomplicated: advertising bans and price rises reduce aggregate demand, education programmes decrease the incidence of uptake, and so on. The messy gestalt is entangled in the explanatory gossamer of a myriad of experiences, conversations, memories, and exposures to interventions, but researchers bearing reductionist precepts and methods wear the equivalent of boxing gloves in their attempt to unravel these delicate threads. 
THE EXPLANATORY PRIVILEGNG OF RECENT FACTORS

It is not just single factors but also recent factors that are privileged by reductionist explanations. The view seems to be that the effects of recent interventions and policy changes could be expected to be less confounded by the intrusion of other influences than policies and events enacted further in the past. This assumption is fuelled by attributions often given by people when they nominate specific events as the reason they stopped smoking-for example, recent illness or symptoms, death of a relative, an intense period of haranguing from their children, a straw that broke the camel's back price rise. Such explanations may well represent accurate and heartfelt perceptions of the precipitating factors that prompted stopping but reveal little of the complex historical precursors that may well have been necessary to predispose people to stop when finally subject to the precipitating event. For example, sensitivity to price increases is probably dependent on a widespread acceptance of the tobacco disease nexus. Respect for the importance of such plausible predisposing factors is rare in evaluative studies about smoking control and was not raised in a recent expert consensus report on research priorities in tobacco pricing and taxation. ${ }^{22}$

\section{CONCERN FOR POLICY TRACTABLE FACTORS}

In recent years concern has been increasingly expressed that research should concentrate on better understanding how to influence so called "policy tractable" factors that influence smoking. These are factors that are amenable to manipulation by government policies and include price, advertising, packaging, laws and regulations on smoking in public places, and school curricula. They stand in contrast with factors said to be also relevant to smoking, which include age, sex, and cultural proscriptions on smoking, social class, occupation, income, performance at school; and smoking by parents, peers, siblings, and workmates. All of these are not as directly or even at all

Pragmatic considerations of what can be directly influenced, schooled from an "upstream" preventive analysis, ${ }^{23}$ have directed research attention to the role of precise factors such as price or large public information campaigns. Again, the problems arising from the reductionism entailed tend to be overlooked in the fervour to produce action oriented research that can be fed into policy and political processes.

\section{RELATION OF EVALUATION TO FUNDING}

Health promotion campaigns that are comparatively expensive are generally subject to intensive scrutiny bred from the competitive funding climates in which they operate. Unlike "passive" preventive strategies such as price controls and advertising restrictions, which require little or no money to implement, health promotion campaigns are continually called on to

The desolate face of smoking in Australia today amenable to influence through government policy. justify their allocation of funds. Evaluation of the

"effects" of funded health education campaigns against smoking are thus partly inspired by a concern to be able to show that an intervention is effective or, better, cost effective. Such considerations produce a highly selective orientation to evaluation driven by logical concerns to assess interventions deemed worthy of evaluation, rather than an attitude towards explaining the cessation process that is open to the possibility of a thoroughly "messy" account such as in the case study.

In many cases these interventions have been organised, developed, and run by the very people who either conduct or commission their evaluation. Often these people are employed on "soft" project funding, which may cease should a political or administrative perception develop that the interventions "don't work." Such considerations raise more tangible concerns about the impartiality of the explanatory process.

\section{CONFOUNDING RUN AMOK}

Individual platforms of comprehensive tobacco control policy are seldom implemented by governments in isolation from others. Exceptions such as the Sudan, where the government banned tobacco advertising but has done virtually nothing else, simply prove the rule: when a government is committed enough to introduce (say) bans on smoking on aircraft it will have done this in a spirit of wanting to reduce the burden of death and illness caused by tobacco and accordingly will be predisposed to introducing other policies with similar intent. In practice this has meant that nearly all countries where evaluation studies of tobacco control policies and programmes have been undertaken have been characterised by the coalescence of a multitude of these factors, much in the manner described in the case study.

Many of these factors will be introduced opportunistically rather than in any way remotely analogous to the timed and controlled drip feeding of drugs in laboratory or clinical trials. Politicians and tobacco control advocates understandably have little or no regard for violating the sanctity of control groups, areas, or periods so coveted by researchers hoping to conduct a neat study unconfounded by unexpected influences. Instead, they are constantly searching for opportunities to engage in media advocacy, to lobby for price rises and further restrictions on advertising, and so on. In large countries such as the United States and Canada, where federal, state, provincial, and local governments have jurisdiction over different elements of tobacco control policy, it is often the case that at any given time quite complex different configurations of tobacco control activity will be being played out in different parts of the country. Some of these events will be newsworthy and picked up by national media networks, which will amplify a local issue into a national concern, thus further corrupting pristine research designs. Most evaluative studies simply pretend that all this does not occur and that the independent variables (policies and interventions) they $\Sigma$

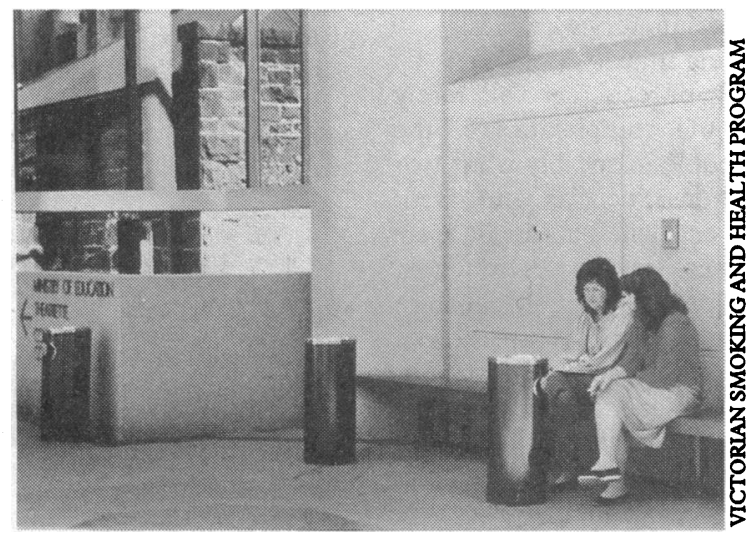

\section{Conclusions}

What does this analysis suggest for the future of evaluation of tobacco control policies and programmes? The sort of methodological problems I have discussed should not induce an evaluative paralysis in tobacco control researchers. They should not inspire any abandonment of the evaluation of outcomes in tobacco control or any shying away from the challenges of the attribution problems. Continuing debate about ways of sampling and controlling for differing "microclimates" of influence and intervention between areas, states, and nations will be very welcome. As well, 


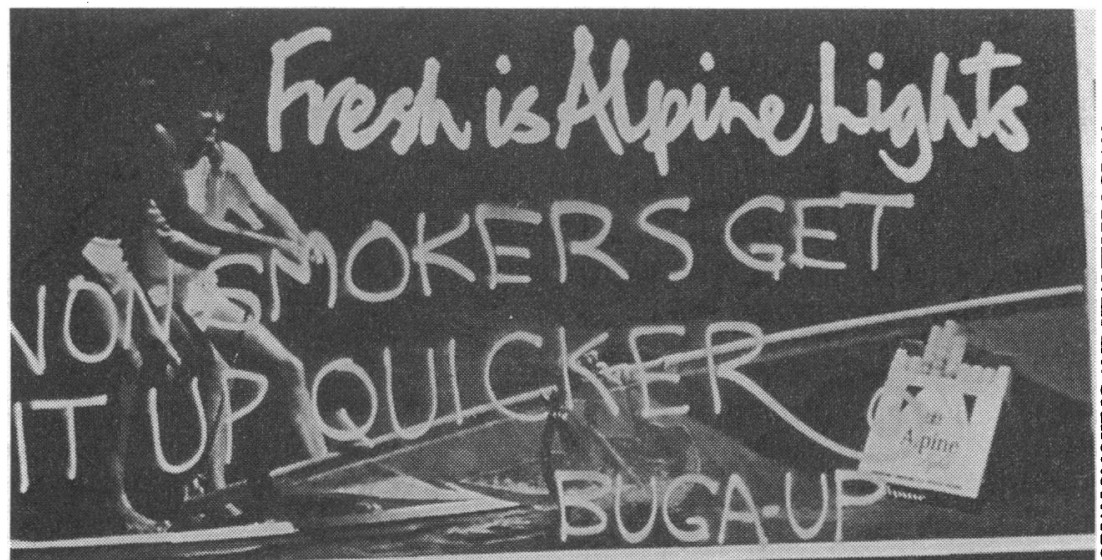

One way that antismoking messages are visible to Australians in everyday life though, a more open recognition of the limitations of reductionist thinking in considering the causes of declining tobacco use throughout populations could redirect researchers into considering the potential of qualitative methods as important adjuncts in the explanatory process.

Mark Twain wrote that if your only tool is a hammer all your problems come to look like nails. And so it has largely been with the dominant explanatory paradigms in smoking control research. Social scientists have long argued for multiple methods or triangulation in studying complex human phenomena. ${ }^{24}$ Triangulated research may use different investigators, theories, and methods to study the one phenomenon, with the assumption that the weaknesses in each single method will be compensated by the counterbalancing strengths of another. This is not to argue that triangulation can ever produce a single "true" reality beyond the frameworks and interpretations provided by each research approach. ${ }^{26}$ Data collection methods and interpretive approaches drawn from ethnomethodology, ${ }^{27}$ oral history, and discourse analysis ${ }^{28}$ hold promise as ways of rendering complex social processes such as the natural course of smoking cessation more transparent. The products of such parallel research would doubtless be examples of what the anthropologist Cliffort Geertz has called "thick description." 29 They would also frequently be culturally and historically specific: understanding the process and motivations of smoking cessation among septuagenarian men in cardiac wards in Cairo will throw up radically different insights from those provided by research into why Australian teenage girls in the age of Madonna are smoking more than their male counterparts..$^{30}$ Such hermeneutic characteristics would doubtless perplex and frustrate some number bound readers hoping for simple, replicable truths and axioms about successful tobacco control. But just as it would be facile to attempt to describe the meaning of Da Vinci's Mona Lisa only in terms of paint and brush strokes, so is it frustrating to consider only tunnel visioned truths tethered to the short leashes of quantifiable explanatory variables.

The degree of analytical complexity possessed by most politicians and funding bureaucrats will rarely require any venturing into the complexities of the attribution problem. Such people invariably want two paragraph answers to questions such as "do these school programmes work?" or "will banning advertising reduce demand?" They are slaves to entrenched, simplified decision making processes that conspire against answers predicated on any honest admission of the highly intertwined nature of the relations involved.

International tobacco control agencies and expert groups, in their wisdom, have long called for comprehensive policies to turn the public tide against tobacco. ${ }^{31} 32$ They have also been dismissive of efforts by the tobacco industry to attribute populationwide trends in tobacco consumption to the presence or absence of single variables-for example, as in the tobacco industry's frequent insistence that the absence of tobacco advertising and the high smoking rates in the former Soviet Union proved that advertising bans did not reduce demand. ${ }^{33}$ The rationale for comprehensive policies lies not in any belief that the individual platforms of such policy (advertising bans, price increases, clean indoor air policy, mandated school health education, strong health warnings, and so on) simply have incremental, additive effects on demand. Rather, it lies in the recognition that each of these platforms are nurtured by the others, creating a synergism which produces the sorts of slide in demand illustrated in the figure and also apparent in countries such as Canada, New Zealand, and Singapore. Probing the dynamics of this synergism using the wider range of research and analytical methods proposed above is long overdue in the professional literature of tobacco control.

1 Department of Community Services and Health. Tobacco in Australia. A summary of related statistics. Canberra: Australian Government Publishing Service, 1990:12.

2 Pierce JP, Dwyer T, Frape G, Chapman S, Chamberlain A, Burke $N$. Evaluation of the Sydney "Quit For Life" anti-smoking campaign. Part 1. Evaluation of the Sydney "Quit For Life" anti-smoking campais
Achievement of intermediate goals. Med f Aust 1986;144:341-4.

3 Chapman $S$, Woodward $S$. Australian court decision on passive smoking upheld on appeal. $B M Y$ 1993;306:102-2.

4 Chapman S. The news on smoking: editorial coverage of tobacco and health issues in Australian newspapers, 1987-88. Am ₹ Public Health 1989;79: 1419-20.

5 White VM, Hill DJ, Williams R. Cigarette and alcohol consumption among Victorian secondary schoolchildren in 1990. Melbourne: Centre for Behavioural Research in Cancer, Anti Cancer Council of Victoria, 1990.

6 Chapman S. Shared accommodation-non-smokers wanted! Tobacco Control 1992;1:248.

7 Brackenridge RDC. Medical selection of life risks. A comprehensive guide to life expectancy for underwriters and clinicians. London: Nature Press, 1985.

8 Mullins R. Smoking restrictions in some of Australia's main companies based in Victoria: an update. Melbourne: Centre for Behavioural Research in Cancer, 1992.

9 Chesterfield-Evans A. Test case for passive smoking. BMF 1992;304:1529.

10 Chapman S, Borland R, Hill D, Owen N, Woodward S. Why the tobacco industry fears the passive smoking issue. Int $\mathcal{f}$ Health Services 1990;20: 417-27.

11 Borland R, Chapman S, Owen N, Hill D. Effects of a workplace smoking ban on the consumption of cigarettes. Am $\mathcal{F}$ Public Health 1990;80:178-80.

12 Chapman S. Smoking in the workplace. Lancet 1992;339:1614.

13 Roberts C, Algert C, Chey T, Capon A, Gray E. Community attitudes to smoking in restaurants. Med $\mathcal{f}$ Aust 1992;157:210.

14 Borland R, Hill D. Public attitudes to smoke-free zones in restaurants: an update. Med F Aust 1991;154:292-3.

5 Anonymous. EPA: butt out of the gutters. Herald-Sun 1992 Mar 4:1.

16 Brownson RC, Chang JC, Davis JR. Cigarette smoking and risk of adult leukemia. Am f Epidemiol 1991;134:938-41.

17 Marlatt GA, Curry S, Gordon JR. A longitudinal analysis of unaided smoking cessation. 7 Consult Clin Psychol 1990;58:310-6.

18 Wilson DH, Wakefield MA, Steven ID, Rorsheim RA, Esterman AJ, Graham NMH. "Sick of smoking": evaluation of a targeted minimal smoking cessation intervention in general practice. Med $\mathcal{F}$ Aust 1990;152:518-21.

19 Hill DJ, White VM, Gray NJ. Australian patterns of tobacco smoking in 1989. Med $\mathcal{F}$ Aust 1991;154:788-9.

20 Gilpin E, Pierce JP, Goodman J, Burns D, Shopland D. Reasons smokers give for stopping smoking: do they relate to success in stopping? Tobacco Control 1992;1:256-63.

21 Chapman S. On the limitations of econometric analysis in cigarette advertising studies. Br F Addict 1989;84:1267-77.

22 Sweanor D, Ballin S, Corcoran RD, Davis A, Deasy K, Ferrence RG, et al. Report of the Tobacco Policy Research Study Group on Tobacco Pricing and Taxation in the United States. Tobacco Control 1992;1 (suppl)S31-6. Thapman S, Bloch M. Preface. Tobacco Control 1992;1:S2-3.

23 Chapman S, Bloch M. Preface. Tobacco Control 1992;1:S2-3.
24 Jick T. Mixing qualitative and quantitative methods: triangulation in action. Administrative Science Quarterly 1979;24:602-11.

25 Brewer J, Hunter A. Multimethod research: a symthesis of style. London: Sage, 1989.

26 Jankowski NW, Wester F. The qualitative tradition in social science inquiry: contributions of mass communications research. In: Jensen KB, Jankowski $\mathrm{NW}$, eds. A handbook of qualitative methodologies for mass communication research. London: Routledge, 1991:44-74.

27 Garfinkel H. Studies in ethnomethodology. Englewood Cliffs, New Jersey: Prentice Hall, 1967.

28 van Dijk TA. Discourse and communication. Berlin: Walter de Gruyter, 1985. 29 Geertz C. The interpretation of culture. New York: Basic Books, 1973.

30 Hill DJ, White VM, Williams RM, Gardner GJ. Tobacco and alcohol use among Australian secondary schoolchildren in 1990. Med $\mathcal{f}$ Aust 1993: among

31 Gray N, Daube M. Guidelines for smoking control. 2nd ed. Geneva: International Union Against Cancer, 1980

32 World Health Organisation. Controlling the smoking epidemic. Tech Rep Ser 1979;636.

33 Chapman S. Anatomy of a campaign: the attempt to defeat the New South Wales (Australia) Tobacco Advertising Prohibition Bill 1991. Tobacco Control 1992;1:50-6.

(Accepted 3 Yune 1993)

.

